\title{
Analisis Hasil Filtering Karous-Hjelt Berdasarkan Beda Spasi Dalam Penggambaran Struktur Bawah Permukaan Tanah
}

\author{
Miftakhul Maulidina \\ Universitas Nusantara PGRI Kediri \\ Email :dhin.na_fisika@yahoo.com
}

Received February 10, 2017; Revised March 1, 2017; Accepted March 9, 2017

\begin{abstract}
Abstrak
Struktur penyusun tanah di setiap wilayah dapat digambarkan melalui pemodelan berdasarkan nilai resistivitas material penyusunnya. Tujuan penelitian ini membuat penggambaran struktur bawah permukaan tanah melalui filtering Karous-Hjelt dengan variasi spasi. Adapun spasi dalam pengambilan data di lapangan adalah spasi 1 dan spasi 0,5 pada masing-masing line. Penelitian ini sekaligus melengkapi hasil penelitian sebelumnya tentang penentuan struktur bawah permukaan tanah di sekitar Candi Gambar Wetan (Maulidina, 2015). Data yang dimasukkan merupakan data hasil pengukuran Very Low Frequency Electromagnetic di area Candi Gambar Wetan. Metode yang digunakan yaitu pengolahan data menggunakan filtering Karous-Hjelt untuk penggambaran struktur bawah permukaan tanah pada kedalaman $0-6$ meter untuk dua jenis data berdasarkan variasi spasi. Hasil pengolahan menunjukkan penggambaran struktur bawah permukaan tanah spasi $0,5 \mathrm{~m}$ memiliki rentang nilai resistivitas yang lebih mendetail dibandingkan spasi $1 \mathrm{~m}$. Hasil ini dapat menambah informasi dan digunakan sebagai acuan dalam penelitian berikutnya.
\end{abstract}

Kata kunci: Filtering Karous-Hjelt, variasi spasi, resistivitas.

\section{Karous-Hjelt Filtering Analysis By Different Spacing To Describe The Structure Of Subsurface}

\begin{abstract}
The subsurface structure in every area can be described by resistivity model of materials. In this research, we made the model of the subsurface structure by Karous-Hjelt Filtering with spacing variation. The spacing of each trajectory was divided into two kinds, 1 meter, and 0,5 meters. The result can complete the previous research about the subsurface structure analysis of Gambar Wetan Temple (Maulidina, 2015). The input data was the measured data of Very Low-Frequency Electromagnetic in Gambar Wetan Temple. The data were filtered by Karous-Hjelt Filtering to describe the subsurface structure at depth 0-6 meter for two kinds of spacing. The results showed that the value of resistivity in spaced 0,5 meters is more specific than the value in spaced 1 meter. This results can help to the next research.
\end{abstract}

Keywords: Karous-Hjelt Filtering, spacing variation, resistivity.

\section{PENDAHULUAN}

Penelitian mengenai struktur bawah permukaan tanah merupakan salah satu jenis penelitian yang dapat dilakukan dengan berbagai macam metode dan berbagai jenis pengolahan data. Pada prinsipnya, cara mendeteksi dan membuat pemodelan adalah perbedaan nilai resistivitas yang ditampilkan dari masingmasing material yang terkandung di dalam tanah (Sungkono, 2014). Resistivitas tanah berkaitan dengan berbagai parameter geologi seperti porositas, mineral dan konten cairan (Singh,
2004) (Martinez, 2009). Untuk mendeteksi struktur penyusun tanah pada kedalaman yang tidak terlalu jauh dari permukaan, metode Very Low Frequency Electromagnetic merupakan metode yang cukup valid dalam pemetaannya. Metode inilah yang telah digunakan dalam pengambilan data di lapangan, yaitu di area Candi Gambar Wetan Kabupaten Blitar (Maulidina, 2015). Pada saat itu, pengambilan data dilakukan dengan variasi satu spasi pada tiap lintasan. Pada penelitian kali ini, peneliti hendak melengkapi hasil penelitian terdahulu dengan memberikan analisis data dengan spasi 1 
meter dan spasi 0,5 meter dari data lapangan dan membuat perbandingan dari variasi spasi tersebut dalam filtering Karous-Hjelt untuk penggambaran struktur bawah permukaan tanah. Hal ini perlu kiranya dijadikan acuan untuk penelitian berikutnya yang menggunakan metode yang lain sehingga nilai resistivitas yang dihasilkan semakin detail.

Filtering data Very Low Frequency Electromagnetic dapat dilakukan antara lain dengan menggunakan Filter Fraser (Fraser, 1969) dan Filter Karous-Hjelt (Karous dan Hjelt, 1983). Dalam penelitian ini sengaja menggunakan Filtering Karous-Hjelt karena Filter Karous-Hjelt merupakan penyempurnaan dari Filter Fraser untuk melokalisisr letak material yang lebih konduktif maupun resistif pada daerah observasi (Bayrak, 2002).

\section{METODE}

Data yang diperoleh dari hasil pengukuran VLF-EM ditulis kembali ke dalam bentuk excel. Data terdiri dari dua jenis, yaitu data untuk spasi 1 meter dan data dengan spasi 0,5 meter pada tiap-tiap lintasan. Lintasan yang dipilih sebanyak 4 lintasan sejajar. Data inphase dan quadrature kemudian diinterpretasikan secara kualitatif menggunakan Filter Karous-Hjelt sehingga dihasilkan profil letak anomali yang lebih konduktif dan resistif pada kedalaman 6 meter. Hasil analisis dari filtering ini berupa profil resistivitas semu 2D yang dapat mencitrakan struktur bawah permukaan tanah.

\section{HASIL DAN PEMBAHASAN}

Berdasarkan data lapangan, didapatkan bahwa data quadrature memiliki amplitudo gelombang yang jauh lebih kecil dibandingkan dengan data inphase sehingga data inphase lebih sensitif terhadap adanya anomali dibandingkan dengan data quadrature. Hal ini sesuai dengan sifat dasar perekaman data VLF-EM bahwa nilai inphase merupakan bagian real dari data dan cukup bagus untuk memetakan konduktivitas secara lateral (Simpson, 2005). Pemetaan tersebut didasarkan pada prinsip gelombang elektromagnetik primer memiliki komponenen medan magnetic yang akan menginduksi medium yang bersifat konduktif di dalam tanah sehingga muncul Eddy Current (Bosch, 2001). Adapun kedalaman penetrasi gelombang yang dapat dicapai dalam perekaman data VLF-EM dapat diformulasikan sebagai berikut:

$$
\delta=\sqrt{\frac{2}{\omega \mu \sigma}} \approx 504 \sqrt{\frac{\rho}{f}}
$$

dimana $\rho$ dan $f$ masing-masing adalah resistivitas bawah permukaan dan frekuensi pemancar (Sungkono, 2014). Oleh karena itu, penggambaran Filter Karous-Hjelt untuk interpretasi kualitatif hanya dilakukan pada data inphase. Berikut penggambaran hasil filtering Karous-Hjelt sebagai interpretasi kualitatif beserta pembahasan pada masing-masing lintasan (line), baik untuk spasi 0,5 meter maupun spasi 1 meter:

\section{A. Spasi 0,5 meter}

\section{1) Line 1}

Pada Gambar 1 terlihat adanya anomali resistif (B) dan anomali konduktif (A,C,D). Anomali resistif ditandai dengan nilai densitas arus yang bernilai positif, sedangkan anomali konduktif memiliki densitas arus negatif.

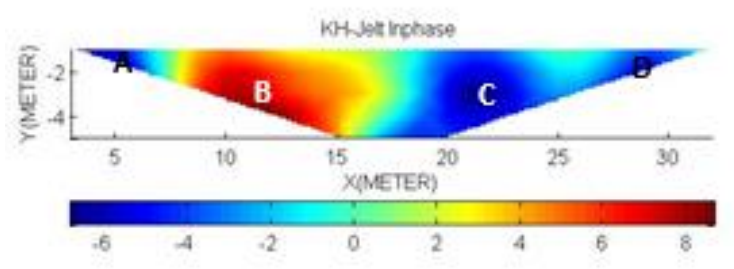

Gambar 1. Hasil Filtering Spasi $1 \mathrm{~m}$ Line 1. 
Jurnal Pendidikan Fisika dan Keilmuan (JPFK) Vol 3 No 1 Maret 2o17, hal 43-47

Avaliable online at : http://e-journal.unipma.ac.id/index.php/JPFK

Print ISSN: 2442-8868, Online ISSN: 2442-904x

2) Line 2

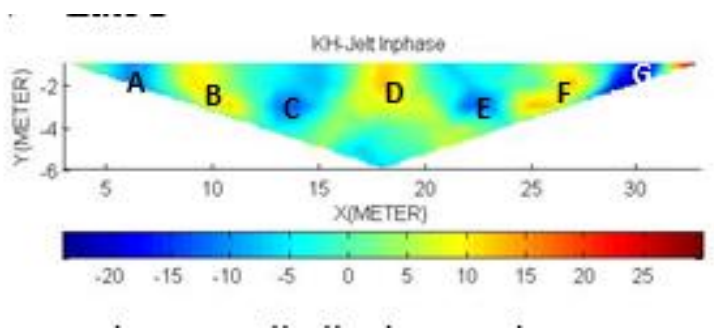

Gambar 2. Hasil Filtering Spasi $1 \mathrm{~m}$ Line 2

Pada Gambar 2 terlihat adanya tiga anomali resistif (B,D,F) dan empat anomali konduktif (A,C,E,G).

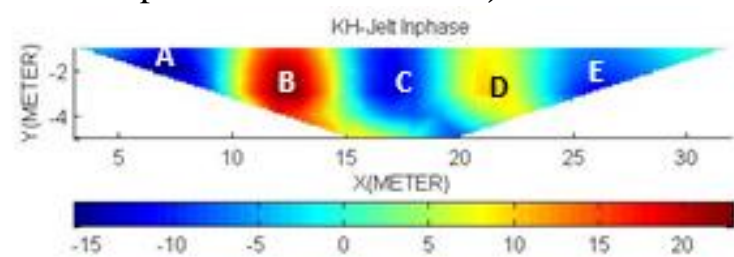

Gambar 3. Hasil Filtering Spasi 1 m Line 3

Pada Gambar 3 teridentifikasi adanya tiga anomali konduktif (A,C,E) dan dua anomali resistif (B,D).

\section{4) Line 4}

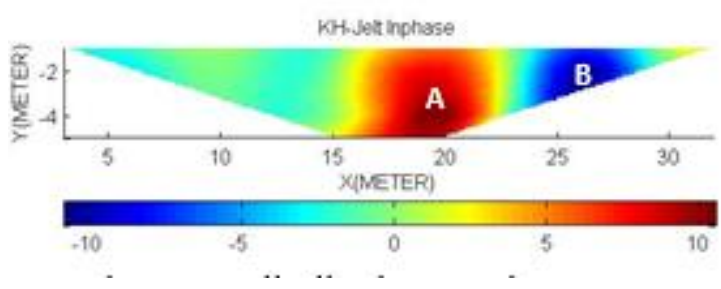

Gambar 4. Hasil Filtering Spasi 1 m Line 4

Pada Gambar 4 teridentifikasi adanya anomali resistif (A) dan anomali konduktif (B).

B. Spasi 0,5 meter
1) Line 1

Pada Gambar 5 teridentifikasi adanya anomali resistif (A,E,F,G,H,I,K) dan anomali konduktif $(\mathrm{B}, \mathrm{D})$.

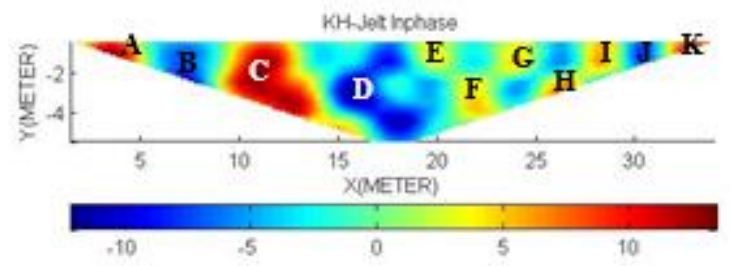

Gambar 5. Hasil Filtering Spasi 0,5 m Line 1 


\section{2) Line 2}

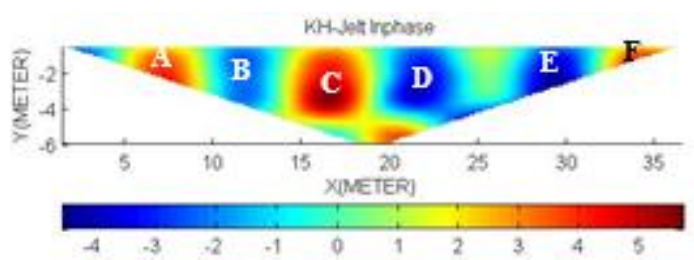

Gambar 6. Hasil Filtering Spasi 0,5 m Line 2

Pada Gambar 6 teridentifikasi adanya anomali resistif (A,C,F) dan anomali 3) Line 3 konduktif $(\mathrm{B}, \mathrm{D}, \mathrm{E})$.

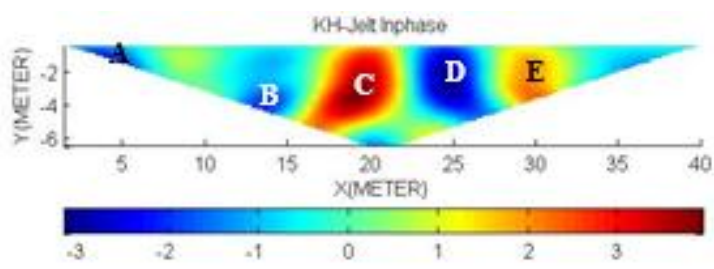

Gambar 7. Hasil Filtering Spasi 0,5 m Line 3

Pada Gambar 7 teridentifikasi adanya anomali resistif (C,E) dan anomali konduktif (A,B,D).

\section{4) Line 4}

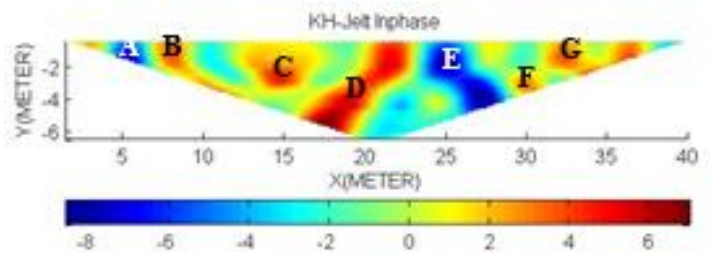

Gambar 8. Hasil Filtering Spasi 0,5 m Line 4

Pada Gambar 8 teridentifikasi adanya anomali resistif $(\mathrm{B}, \mathrm{C}, \mathrm{D}, \mathrm{F}, \mathrm{G})$ dan anomali konduktif $(\mathrm{A}, \mathrm{E})$.

\section{KESIMPULAN}

Pada masing-masing lintasan (line) terdapat dua jenis anomali yang terdeteksi, yaitu anomali resistif yang memiliki nilai resistivitas lebih tinggi daripada daerah sekitar dan anomali konduktif yang memiliki resistivitas lebih rendah daripada daerah sekitarnya. Secara umum, anomali resistif yang ditampilkan oleh spasi 0,5 meter lebih mendetail daripada hasil yang ditunjukkan oleh spasi 1 meter.

\section{DAFTAR PUSTAKA}

Bayrak, M. (2002). "Exploration of chrome ore in Southwestern Turkey by VLF-EM". Vol. 5. Hal. 35-46.

Bosch, I. M. F. P. (2001). "Continuous gradient VLF measurements: a new possibility for high resolution mapping of karst structures". First Break. Vol. 19. No. 6.

Karous, M. dan S. E. Hjelt. (1983). "Linear Filtering of Vlf Dip-Angle Measurements". Geophysics Prospect. Vol. 31. No. 5. Hal. 782-794.

Martinez-Pagan, P., Faz Cano, Aracil, dan Arocena J. M.. (2009). "Electrical Resistivity Imaging Revealed The Spatial Properties Of Mine Tailing Ponds In The Sierra Minera of Southeast Spain'. Journal Environ. Eng. Gephys. Vol. 14. No. 2. Hal. 63-76.

Maulidina, M., Bagus Jaya S., dan Sungkono. (2015). "The Subsurface Structure Analysis of Gambar Wetan Temple, Blitar Using Very Low Frequency Electromagnetic (VLF-EM) Method". Prosiding “The $2^{\text {nd }}$ International Conference on Research, Implementation, 
Jurnal Pendidikan Fisika dan Keilmuan (JPFK) Vol 3 No 1 Maret 2o17, hal 43-47

Avaliable online at : http://e-journal.unipma.ac.id/index.php/JPFK

Print ISSN: 2442-8868, Online ISSN: 2442-904x

and Education of Mathematics and Sciences 2015 ( $2^{\text {nd }}$ ICRIEMS)”. Yogyakarta.

Simpson, F. dan K. Bahr. (2005). Practical Magnetotellurics. New York. Cambridge University Press.

Singh, K. K. K., K. B. Singh, dan A. Prakash. (2004). "Multielectrode resistivity imaging technique for the study of coal seam." Journal Science Ind. Res.. Vol. 63. No. 11. Hal. 927-930.

Sungkono, A. Husein, H. Prasetyo, A.S. Bahri, F.A. Santos, and B.J. Santosa. (2014). "The VLF-EM imaging of potential collapse on the LUSI embankment". Journal of Applied Geophysics. Vol. 109. Hal. 218-232. 